Pulpotomi tedavisi uygulanan süt dişlerinin klinik ve radyolojik değerlendirilmesi

\section{Clinical and radiographic evaluation of the success of primary teeth treated with pulpotomy}

\author{
Dr. Öğr. Üyesi Sema Aydınoğlu \\ Recep Tayyip Erdoğan Üniversitesi \\ Diş Hekimliği Fakültesi, Pedodonti A.D., Rize \\ Orcid ID: 0000-0003-1490-8645
}

\section{Arş. Gör. Dt. Tuğçe Doğan}

Recep Tayyip Erdoğan Üniversitesi

Diş Hekimliği Fakültesi, Pedodonti A.D., Rize

Orcid ID: 0000-0003-0479-4066

\section{Dr. Öğr. Üyesi İpek Arslan}

Recep Tayyip Erdoğan Üniversitesi

Diş Hekimliği Fakültesi, Pedodonti A.D., Rize

Orcid ID: 0000-0002-8648-3554

Geliş tarihi: 26 Kasım 2020

Kabul tarihi: 11 Mart 2021

doi: 10.5505/yeditepe.2022.26879

\section{Yazışma adresi:}

Dr. Öğr. Üyesi Sema Aydınoğlu

RTEÜ Diş Hekimliği Fakültesi Pedodonti AD,

Rize, Türkiye

Tel: 05368381138

E-posta: semapilak@hotmail.com

\section{ÖZET}

Amaç: Süt dişlerinde uygulanan pulpotomi tedavilerinin ve üst restorasyonlarının başarıları ile bu tedavilerin daimi dişlerin gelişim ve sürme sürecine etkilerinin değerlendirilmesi amaçlanmaktadır.

Gereç ve Yöntem: Çalışmaya Recep Tayyip Erdoğan Üniversitesi Diş Hekimliği Fakültesi Çocuk Diş Hekimliği Kliniği'ne 01.01.2017 - 31.12.2018 tarihleri arasında başvuran 270 hasta dahil edildi. Restorasyonların başarısı USPHS Kriterlerine göre değerlendirildi. Tedavi uygulanan süt dişinin altındaki daimi diş germi ile kontralateral simetrik daimi dişe bakılarak sürme zamanları karşılaştıııldı. Erüpsiyonunu tamamlayan daimi dişler hipoplazi ve/veya rotasyon varlığı açısından incelendi. İstatistiksel analizlerde Ki-kare ve McNemar testleri kullanıldı. Bulgular: Pulpotomi uygulanan süt dişlerinden maksiller birinci azıların diğer dişlere kıyasla ağızda bulunma oranlarının anlamlı derecede düşük olduğu gözlendi $(p<0,001)$. Takip süresi uzadıkça (>24 ay) süt dişlerinde görülen kayıp yüzdelerinin arttığı belirlendi $(p<0,001)$. Cam iyonomer uygulanan dişlerin istatistiksel açıdan anlamlı şekilde ağızda olmadığı görüldü $(p=0,046)$. Lisans öğrencilerinin pulpotomi uyguladığı süt dişlerinin ağızda bulunma oranlarının uzmanlık öğrencilerine kıyasla daha düşük olduğu tespit edildi $(p=0,004)$. USPHS kriterlerine göre kenar uyumu açısından diğer materyallere kıyasla kompozitlerin daha iyi olduğu $(p=0,039)$, ancak kompozit restorasyonların mine dokusuna göre daha pürüzlü oldukları belirlendi $(p=0,015)$. Hekim tecrübesi ile retansiyon, anatomik form ve yüzey pürüzlülük değerleri açısından anlamlı ilişki tespit edildi ( $p=0,012 ; p=0,034 ; p=0,001)$.

Sonuç: Üst restorasyonda kullanılan materyalin çeşidi ile tedaviyi uygulan hekimin klinik tecrübe ve becerisi pulpotomi uygulamalarında başarıyı etkileyen önemli faktörlerdendir.

Anahtar kelimeler: Pulpotomi, USPHS, süt dişi, cam iyonomer, amputasyon.

\section{SUMMARY}

Aim: To evaluate the success of pulpotomy treatments and their restorations applied in primary teeth and the effects on the development and eruption of permanent teeth.

Materials and Methods: Two hundred and seventy patients who referred to Recep Tayyip Erdogan University, Faculty of Dentistry, Department of Pediatric Dentistry between 01.01.2017 and 31.12.2018 were included in the study. The success of the restorations was evaluated using the USPHS Criteria. The eruption times were compared by examining the permanent teeth germs under the treated primary teeth. Permanent teeth that completed their eruption were examined for the presence of hypoplasia and/or rotation. Chi-square and McNemar tests were used for statistical analysis.

Results: It was observed that the presence of maxillary first molars treated with pulpotomy was found to be significantly lower than the others $(p<0.001)$. A longer follow up period ( $>24$ months) increased the percentage of loss in primary teeth $(p<0.001)$. Teeth treated with glass ionomer were sig- 
nificantly lost $(p=0,046)$. The primary teeth that undergraduate students treated with pulpotomy lost more than the residents $(p=0.004)$. According to the USPHS criteria, composites were better than other materials $(p=0.039)$ in terms of marginal adaptation, but composite restorations were rougher than enamel $(p=0.015)$. A significant relationship was found in terms of retention, anatomical form and surface roughness with the dentist's experience $(p=0.012 ; p=0.034 ; p=0.001)$.

Conclusion: Type of material used in dental restorations and the clinical experience and skill of the dentist who applied the treatment are important factors affecting the success of pulpotomy.

Key words: Pulpotomy, USPHS, primary teeth, glass ionomer, amputation.

\section{GíRiş}

Daimi dişler için yer tutucu görevi gören, çiğneme hareketleri ile çenelerin vertikal gelişimlerini stimüle eden, çocuğun beslenme, büyüme ve gelişimine katkıda bulunan süt dişleri, fonasyon ve estetik açıdan da önem taşımaktadır. Erken süt dişi kaybı, azalmış çiğneme fonksiyonu, yer kaybı, malokluzyon, konuşma bozuklukları, psikolojik rahatsızlıklar, atipik dil alışkanlıkları gibi istenmeyen durumlara sebep olabilmektedir. ${ }^{2}$ Süt dişlerinin tedavi edilerek, daimi dişler sürene kadar diş arkında işlevlerinin sürdürülmesi ile bu problemlerin önüne geçilmektedir. ${ }^{2}$

Derin çürüklü süt dişlerinde, çürüğün temizlenmesi sırasında pulpanın açıldığı ancak kök pulpasının sağlıklı olduğu ve iyileşme kapasitesini koruduğu durumlarda uygulanan tedavi seçeneklerinden birisi olan pulpotomi; çürükten etkilenmiş ve inflamasyon gözlenen kuron pulpasının çıkartılarak kalan sağlıklı kök pulpasının üzerine pulpanın vitalitesini koruyacak ya da fiksasyonunu sağlayacak bir kapaklama ajanı örtülmesi işlemidir. ${ }^{3,4}$ Ideal bir kapaklama ajanı; bakterisit, biyouyumlu, kök pulpasının iyileşmesine yardımcı ve fizyolojik kök rezorpsiyonu ile benzer hızda rezorbe olmalıdır, fakat bu şartları tam olarak sağlayan ideal bir kaplama ajanı henüz bulunamamışıır. ${ }^{2}$ Pulpotomi uygulamalarında sıkça tercih edilen non-aldehit grubu ve güçlü bir hemostatik ajan olan demir sülfatın klinik başarısının yüksek olduğu gösterilmiştir. ${ }^{5}$ Pulpaya direkt uygulanan solusyonun asidik $\mathrm{pH}^{\prime} \mathrm{s}$ n nedeniyle demir ve sülfat iyonları açığa çıkmaktadır. Pulpa dokusu üzerinde meydana gelen metal-protein pıhtısı irritan komponentlere karşı nontoksik bir bariyer olarak görev yapmaktadır. ${ }^{6}$

Süt dişi pulpotomi uygulamalarında tedavi başarısının, çocuğun yaşına, kuron ve kök pulpasındaki enflamasyonun şiddetine, kök rezorpsiyonunun derecesine, kullanılan teknik ve pulpotomi materyalinin niteliğine, geçici ya da daimi restorasyonların özelliğine, gözlem süresi ve hekimin tecrübesine bağlı olduğu gösterilmiştir.7,8

Klinik olarak semptom göstermeyen, radyolojik olarak herhangi bir periradiküler lezyon, patolojik rezorpsiyon gözlenmeyen ve daimi diş gelişimini tamamlayana kadar çiğneme fonksiyonuna katkıda bulunan süt dişlerine yapılan tedaviler başarılı bulunmaktadır. Ağrı, perküsyon duyarlığı, mobilite, ödem ve fistül gibi semptomların bir veya daha fazlasının gözlendiği süt dişlerine yapılan pulpotomi uygulamaları ise radyolojik olarak patolojik bulgu varlığına bakılmaksızın başarısız olarak kabul edilmektedir. ${ }^{9-11}$ Endodontik tedavi sonrası uygun yapılmayan restorasyonlar koronal mikrosızıntıya sebep olarak tedavinin başarısızlığında rol oynayan faktörlerin başında gelmektedir.12 Bu nedenle endodontik tedavi sonrası artmış kırılganlığın ve aşırı madde kaybının gözlendiği süt dişlerinde meydana gelebilecek post-operatif kuron fraktürlerinin ve özellikle mikrosızıntının engellenebilmesi için dişlerin fiziksel özellikleri güçlü bir materyalle restore edilmesi önerilmektedir. ${ }^{13-15}$ Ayrıca; tedavi sırasında olduğu kadar tedavi öncesi ve sonrasında hekimin el alışkanlığı ve becerisinin de tedavi başarısında önemli rolü olduğu belirtilmektedir. ${ }^{16}$

Süt dişlerine uygulanan pulpotomi tedavilerinin daimi dişler üzerine olan etkileri ve pulpotomi tedavisi sonrası uygulanan restorasyonlarının klinik başarılarını değerlendiren çalışmaların sınırlı sayıda olduğu görülmektedir. Bu çalışmada süt dişlerinde sıklıkla uygulanan pulpotomi tedavilerinin ve üst restorasyonlarının başarıları ile bu tedavilerin daimi dişlerin gelişim ve sürme sürecine olan etkilerinin değerlendirilmesi amaçlanmaktadır.

\section{GEREÇ ve YÖNTEM}

\section{Etik Kurul Onayı}

Çalışma Recep Tayyip Erdoğan Üniversitesi Tıp Fakültesi Klinik Araştırmalar Etik Kurulu tarafından onaylandı (Karar No: 2018/106). Çalışma öncesinde bilgilendirilmiş onam formları ebeveynlere imzalatıldı.

\section{Araştırmanın Şekli ve Yeri}

Çalışma, Recep Tayyip Erdoğan Üniversitesi Diş Hekimliği Fakültesi Çocuk Diş Hekimliği Kliniği'ne 01.01.2017 31.12.2018 tarihleri arasında başvuran süt dişi pulpotomi tedavisi gören, sistemik olarak sağlıklı, herhangi bir mental rahatsızlığı olmayan ve çalışmaya katılmayı kabul eden 270 hastanın verileri değerlendirilerek yapıldı. Demografik bilgiler kaydedildi. Daha sonra ve pulpotomi tedavisi uygulanan dişler klinik ve radyolojik olarak incelendi.

Belirtilen tarih aralığında pulpotomi tedavisi uygulanan hastalar telefonla aranarak araştırma hakkında bilgi verildi ve çocuklar rutin muayeneleri için kliniğe çağrıldı. Hastaların ağız içi muayenelerinde pulpotomi tedavisi uygulanan süt dişi ağızda ise ilgili diş gingival enflamasyon, mobilite, perküsyon/palpasyon hassasiyeti, fistül ve ödem varlığı açısından değerlendirildi. Restorasyonların başarısı Modifiye Ryge (USPHS) Kriterleri kullanılarak değerlendirildi. ${ }^{17}$ Tedavi edilen dişler radyolojik olarak eksternal/internal kök rezorbsiyonu, bifurkasyon/periapikal lezyon varlığı açısından değerlendirildi. Tedavi uygulanan süt dişinin 
altındaki daimi diş germi ile kontralateral simetrik dişe bakılarak sürme zamanları karşılaştırıldı. Altındaki daimi diş sürmediği halde çekilmiş olduğu tespit edilen pulpotomi tedavisi uygulanan süt dişleri erken kayıp olarak kayıt altına alındı. Erüpsiyonunu tamamlayan daimi dişler hipoplazi ve/veya rotasyon varlığı açısından incelendi.

\section{istatistiksel Analiz}

Elde edilen veriler SPSS (Statistical Package for the Social Sciences, SPSS Inc. Chicago, IL, USA) 23.0 istatistik paket programı kullanılarak değerlendirildi. Tanımlayıcı değişkenlere ait verilerin analizinde frekans ve yüzdesel dağılımları verildi. Gruplar arasındaki farklılıkların karşılaştırılmasında Ki-kare testi kullanıldı. Olası tüm çoklu karşılaştırmalarda Tip I hatayı kontrol edebilmek için Bonferroni Düzeltmesi yapıldı. Bağımlı verilerin karşılaştırılmasında McNemar testi kullanıldı. $\mathrm{p}<0,05$ değeri istatistiksel olarak anlamlı kabul edildi.

\section{BULGULAR}

Çalışmaya katılan 270 hastanın \%43'ünün kız, \%57'sinin ise erkek olduğu tespit edildi. Kızlarda 9,34ะ1,43 olan yaş

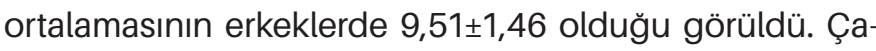
ışmada yer alan diğer verilerin dağılımı Tablo 1'de gösterilmektedir.

Tablo 1. Çalışma verilerinin dağııımı.

\begin{tabular}{|c|c|c|}
\hline & n & $\%$ \\
\hline \multicolumn{3}{|l|}{ Cinsiyet } \\
\hline $\mathrm{K}_{1 z}$ & 116 & 43,0 \\
\hline Erkek & 154 & 57,0 \\
\hline \multicolumn{3}{|l|}{ Pulpotomi uygulanan süt dişi } \\
\hline Üst birinci süt azı & 66 & 24,4 \\
\hline Üst ikinci süt azı & 58 & 21,5 \\
\hline Alt birinci süt azı & 86 & 31,9 \\
\hline Alt ikinci süt azı & 60 & 22,2 \\
\hline \multicolumn{3}{|l|}{ Takip süresi } \\
\hline $12-24$ ay & 128 & 47,4 \\
\hline$>24$ ay & 142 & 52,6 \\
\hline \multicolumn{3}{|l|}{ Restorasyon } \\
\hline Cam iyonomer siman & 85 & 31,5 \\
\hline Kompomer & 93 & 34,4 \\
\hline Kompozit & 92 & 34,1 \\
\hline \multicolumn{3}{|l|}{ Uygulayan hekim } \\
\hline Dönem V Lisans öğrencisi & 90 & 33,3 \\
\hline Uzmanlık öğrencisi & 90 & 33,3 \\
\hline Uzman & 90 & 33,3 \\
\hline \multicolumn{3}{|c|}{ Pulpotomi uygulanan dişin ağız içerisindeki varlığı } \\
\hline Süt diși yerinde bulunmamaktadır. & 120 & 44,4 \\
\hline Süt dişi yerinde bulunmaktadır. & 150 & 55,6 \\
\hline Toplam & 270 & 100 \\
\hline
\end{tabular}

Pulpotomi uygulanan dişlerin ağızda bulunma durumu ile cinsiyet arasında istatistiksel olarak anlamlı bir ilişki bulunmadı ( $p>0,05)$ (Tablo 2).
Tablo 2. Pulpotomi uygulanan dișlerin ağızda bulunma durumu ile çalıșma verilerinin karşılaştırılması.

\begin{tabular}{|c|c|c|c|c|}
\hline & \multicolumn{4}{|c|}{ Pulpotomi uygulanan diş } \\
\hline & $\begin{array}{c}\text { Ağızda yok } \\
\text { n (\%) }\end{array}$ & $\begin{array}{c}\text { Ağızda var } \\
\text { n(\%) }\end{array}$ & $\begin{array}{c}\text { Toplam } \\
\text { n }\end{array}$ & p değeri \\
\hline \multicolumn{5}{|l|}{ Cinsiyet } \\
\hline $\mathrm{Kız}$ & $52(44,8)$ & $64(55,2)$ & 116 & \multirow{2}{*}{0,912} \\
\hline Erkek & $68(44,2)$ & $86(55,8)$ & 154 & \\
\hline \multicolumn{5}{|c|}{ Pulpotomi uygulanan süt dişi } \\
\hline Üst birinci süt azı & $42(63,6)$ & $24(36,4)$ & 66 & \multirow{4}{*}{$<0,001^{* *}$} \\
\hline Üst ikinci süt azı & $19(32,8)$ & $39(67,2)$ & 58 & \\
\hline Alt birinci süt azı & $41(47,7)$ & $45(52,3)$ & 86 & \\
\hline Alt ikinci süt azı & $18(30,0)$ & $42(70,0)$ & 60 & \\
\hline \multicolumn{5}{|l|}{ Takip süresi } \\
\hline $12-24$ ay & $20(15,6)$ & $108(84,4)$ & 128 & \multirow{2}{*}{$<0,001^{* *}$} \\
\hline$>24$ ay & $100(70,4)$ & $42(29,6)$ & 142 & \\
\hline \multicolumn{5}{|l|}{ Restorasyon } \\
\hline Cam iyonomer siman & $47(55,3)$ & $38(44,7)$ & 85 & \multirow{3}{*}{$0,046^{*}$} \\
\hline Kompomer & $35(37,6)$ & $58(62,4)$ & 93 & \\
\hline Kompozit & $38(41,3)$ & $54(58,7)$ & 92 & \\
\hline \multicolumn{5}{|l|}{ Uygulayan hekim } \\
\hline Dönem V Lisans öğrencisi & $52(57,8)$ & $38(42,2)$ & 90 & \multirow{3}{*}{$0,004^{* *}$} \\
\hline Uzmanlık öğrencisi & $30(33,3)$ & $60(66,7)$ & 90 & \\
\hline Uzman & $38(42,2)$ & $52(57,8)$ & 90 & \\
\hline
\end{tabular}

$* p<0,05 * * p<0,001$

Pulpotomi uygulanan süt dişlerinden üst birinci azıların diğer dişlere kıyasla ağızda bulunma oranlarının anlamlı derecede düşük olduğu gözlendi $(p<0,001)$. Takip süresi uzadıkça (>24 ay) süt dişlerinde görülen kayıp yüzdelerinin arttığı belirlendi $(p<0,001)$.

Üç farklı restoratif materyal arasından cam iyonomer uygulanan dişlerin istatistiksel açıdan anlamlı şekilde ağızda bulunmadığı görüldü $(p=0,046)$. Uzman diş hekimleri ile lisans ve uzmanlık öğrencileri arasında anlamlı bir ilişki bulunmadı ( $p>0,05)$. Ancak lisans öğrencilerinin pulpotomi uyguladığı süt dişlerinin ağızda bulunma oranlarının uzmanlık öğrencilerine kıyasla daha düşük olduğu tespit edildi ( $p=0,004)$.

Tablo 3. Yapılan restorasyonların USPHS kriterlerine göre dağılımı.

\begin{tabular}{|c|c|c|c|c|}
\hline & $\begin{array}{c}\text { Alpha (A) } \\
\text { n }(\%)\end{array}$ & $\begin{array}{c}\text { Bravo (B) } \\
\text { n (\%) }\end{array}$ & $\begin{array}{c}\text { Charlie (C) } \\
\text { n (\%) }\end{array}$ & $\begin{array}{c}\text { Toplam } \\
\text { n (\%) }\end{array}$ \\
\hline Retansiyon & $144(96,0)$ & $4 \quad(2,7)$ & $2 \quad(1,3)$ & $150(100)$ \\
\hline Renk uyumu & $65 \quad(43,3)$ & $80 \quad(53,3)$ & $5 \quad(3,3)$ & $150(100)$ \\
\hline Kenar renklenmesi & $60 \quad(40,0)$ & $85 \quad(56,7)$ & $5 \quad(3,3)$ & $150(100)$ \\
\hline Kenar uyumu & $73 \quad(48,7)$ & $63 \quad(42,0)$ & $14(9,3)$ & $150(100)$ \\
\hline Sekonder çürük & $119(79,3)$ & $30 \quad(20,0)$ & $1 \quad(0,7)$ & $150(100)$ \\
\hline Anatomik form & $65 \quad(43,3)$ & $73 \quad(48,7)$ & $12(8,0)$ & $150(100)$ \\
\hline Postoperatif hassasiyet & $134(89,3)$ & $15(10,0)$ & $1 \quad(0,7)$ & $150(100)$ \\
\hline Yüzey pürüzlülü̈̆̈̈ & $37 \quad(24,7)$ & $93 \quad(62,0)$ & $20 \quad(13,3)$ & $150(100)$ \\
\hline
\end{tabular}

Tablo 3'te USPHS kriterlerine göre pulpotomi uygulanan dişlerin üst restorasyonlarının dağılımı gösterildi. Kullanılan restoratif materyaller USPHS kriterlerine göre retansiyon, renk uyumu, marjinal kenar renklenmesi, marjinal kenar uyumu, sekonder çürük, postoperatif hassasiyet, anatomik form ve yüzey pürüzlülüğü açısından değerlendirildi (Tablo 4). 
Tablo 4. USPHS kriterleri ile kullanılan restoratif materyal arasındaki ilişkinin değerlendirilmesi.

\begin{tabular}{|c|c|c|c|c|c|c|c|c|}
\hline & & is & & $\begin{array}{l}\text { MPOMER } \\
\%\end{array}$ & $\begin{array}{l}\text { KO } \\
\mathrm{n}\end{array}$ & $\begin{array}{l}\text { MPOZIT } \\
\%\end{array}$ & $\begin{array}{c}\text { Toplam } \\
\text { n }\end{array}$ & p değeri \\
\hline \multicolumn{9}{|c|}{ Retansiyon } \\
\hline A & 37 & $(25,7)$ & 54 & $(37,5)$ & 53 & $(36,8)$ & 144 & \multirow{3}{*}{0,100} \\
\hline B & 0 & (0) & 4 & (100) & 0 & (0) & 4 & \\
\hline C & 1 & $(50,0)$ & 0 & (0) & 1 & $(50,0)$ & 2 & \\
\hline \multicolumn{9}{|c|}{ Renk uyumu } \\
\hline A & 16 & $(24,6)$ & 28 & $(43,1)$ & 21 & $(32,3)$, & 65 & \multirow{3}{*}{0,193} \\
\hline B & 21 & $(26,3)$ & 26 & $(32,5)$ & 33 & $(41,3)$ & 80 & \\
\hline $\mathrm{C}$ & 1 & $(20,0)$ & 4 & $(80,0)$ & 0 & (0) & 5 & \\
\hline \multicolumn{9}{|c|}{ Kenar renklenmesi } \\
\hline A & 14 & $(23,3)$ & 21 & $(35,0)$ & 25 & $(41,7)$ & 60 & \multirow{3}{*}{0,278} \\
\hline B & 23 & $(27,1)$ & 33 & $(38,8)$ & 29 & $(34,1)$ & 85 & \\
\hline $\mathrm{C}$ & 1 & $(20,0)$ & 4 & $(80,0)$ & 0 & (0) & 5 & \\
\hline \multicolumn{9}{|c|}{ Kenar uyumu } \\
\hline A & 15 & $(20,5)$ & 27 & $(37,0)$ & 31 & $(42,5)$ & 73 & \multirow{3}{*}{$0,039 *$} \\
\hline B & 18 & $(28,6)$ & 22 & $(34,9)$ & 23 & $(36,5)$ & 63 & \\
\hline C & 5 & $(35,7)$ & 9 & $(64,3)$ & 0 & (0) & 14 & \\
\hline \multicolumn{9}{|c|}{ Sekonder çürük } \\
\hline A & 28 & $(23,5)$ & 47 & $(39,5)$ & 44 & $(37,0)$ & 119 & \multirow{3}{*}{0,478} \\
\hline B & 9 & $(30,0)$ & 11 & $(36,7)$ & 10 & $(33,3)$ & 30 & \\
\hline C & 1 & $(100)$ & 0 & (0) & 0 & (0) & 1 & \\
\hline \multicolumn{9}{|c|}{ Anatomik form } \\
\hline $\mathbf{A}$ & 15 & $(23,1)$ & 23 & $(35,4)$ & 27 & $(41,5)$ & 65 & \multirow{3}{*}{0,071} \\
\hline B & 17 & $(23,3)$ & 29 & $(39,7)$ & 27 & $(37,0)$ & 73 & \\
\hline $\mathrm{C}$ & 6 & $(50,0)$ & 6 & $(50,0)$ & 0 & (0) & 12 & \\
\hline \multicolumn{9}{|c|}{ Postoperatif hassasiyet } \\
\hline $\mathbf{A}$ & 35 & $(26,1)$ & 52 & $(38,8)$ & 47 & $(35,1)$ & 134 & \multirow{3}{*}{0,361} \\
\hline B & 2 & $(13,3)$ & 6 & $(40,0)$ & 7 & $(46,7)$ & 15 & \\
\hline C & 1 & $(100)$ & 0 & (0) & 1 & (1) & 1 & \\
\hline \multicolumn{9}{|c|}{ Yüzey pürüzlüllüğü } \\
\hline A & 10 & $(27,0)$ & 19 & $(51,4)$ & 8 & $(21,6)$ & 37 & \multirow{3}{*}{$0,015^{*}$} \\
\hline B & 20 & $(21,5)$ & 30 & $(32,3)$ & 43 & $(46,2)$ & 93 & \\
\hline C & 8 & $(40,0)$ & 9 & $(45,0)$ & 3 & $(15,0)$ & 20 & \\
\hline
\end{tabular}

$* \mathrm{p}<0,05 * * \mathrm{p}<0,001$

Buna göre kenar uyumu açısından kompozitlere kıyasla kompomer ve cam iyonomer ile yapılan restorasyonlarda dentin dokusunu içeren açıklıkların anlamlı şekilde daha fazla olduğu görüldü $(p=0,039)$. Diğer materyallere kıyasla kompozit restorasyonların mine dokusuna göre daha pürüzlü oldukları belirlendi $(p=0,015)$. Diğer kriterler ve restoratif materyaller arasında istatistiksel açıdan anlamlı bir fark bulunmadı $(p>0,05)$

Takip süresi ile uygulayan hekim ve restorasyon materyalleri arasındaki ilişki Tablo 5'de gösterilmektedir.

Tablo 5. Takip süresi ile uygulayan hekim ve restoratif materyal arasındaki ilişkinin değerlendirilmesi.

\begin{tabular}{|c|c|c|c|c|c|c|}
\hline & \multicolumn{2}{|c|}{$12-24$ ay } & \multicolumn{2}{|c|}{$>24$ ay } & \multirow{2}{*}{$\begin{array}{c}\text { Toplam } \\
\mathbf{n}\end{array}$} & \multirow{2}{*}{ p değeri } \\
\hline & $\mathbf{n}$ & $\%$ & $\mathbf{n}$ & $\%$ & & \\
\hline \multicolumn{7}{|l|}{ Uygulayan hekim } \\
\hline Dönem V Lisans öğrencisi & 40 & $(44.9)$ & 49 & (55.1) & 89 & \multirow{3}{*}{$<0,001^{* * *}$} \\
\hline Uzmanlık öğrencisi & 60 & $(65.9)$ & 31 & $(34.1)$ & 91 & \\
\hline Uzman & 28 & $(31.1)$ & 62 & (68.9) & 90 & \\
\hline \multicolumn{7}{|l|}{ Restorasyon } \\
\hline Cam iyonomer siman & 27 & $(31.8)$ & 58 & $(68.2)$ & 85 & \multirow{3}{*}{$0,001 *$} \\
\hline Kompomer & 47 & $(50.5)$ & 46 & $(49.5)$ & 93 & \\
\hline Kompozit & 54 & $(58.7)$ & 38 & (41.3) & 92 & \\
\hline
\end{tabular}

$\star p<0,05 * * p<0,001$

Yapılan pulpotomi işlemi sonrası uzmanların tedavi ettiği dişlerin takip sürelerinin 24 aydan fazla olduğu, uzmanlık öğrencilerinin uygulama yaptığı dişlerin takip sürelerinin ise istatistiksel açıdan anlamlı şekilde 12-24 ay arasında olduğu gözlendi $(p<0,001)$. Uygulanan restorasyon materyalleri arasında cam iyonomerlerin kompomer ve kompozitlere göre anlamlı düzeyde takip sürelerinin fazla olduğu saptandı $(p=0,001)$.
USPHS kriterlerine göre pulpotomi uygulamasını yapan hekim ile restorasyonların başarısı Tablo 6'te gösterildi.

Tablo 6. USPHS kriterleri ile pulpotomi uygulayan hekim arasındaki ilişkinin değerlendirilmesi.

\begin{tabular}{|c|c|c|c|c|c|c|c|}
\hline & $\begin{array}{c}\text { Dönem V } \\
\text { Lisans } \\
\text { öğrencisi }\end{array}$ & \multicolumn{2}{|c|}{$\begin{array}{l}\text { Uzmanlık } \\
\text { öğrencisi }\end{array}$} & \multicolumn{2}{|c|}{ Uzman } & \multirow[t]{2}{*}{ Toplam } & \multirow[t]{2}{*}{ p değeri } \\
\hline & n $\%$ & n & $\%$ & $\mathbf{n}$ & $\%$ & & \\
\hline \multicolumn{8}{|c|}{ Retansiyon } \\
\hline $\mathbf{A}$ & $63(43,8)$ & 60 & $(41,7)$ & 21 & $(14,6)$ & 144 & \multirow{3}{*}{$0,012^{*}$} \\
\hline B & $3 \quad(75,0)$ & 1 & $(25,0)$ & 0 & (0) & 4 & \\
\hline $\mathrm{C}$ & $0 \quad(0)$ & 0 & $(0)$ & 2 & (100) & 2 & \\
\hline \multicolumn{8}{|c|}{ Renk uyumu } \\
\hline $\mathbf{A}$ & $25(38,5)$ & 25 & $(38,5)$ & 15 & $(23,1)$ & 65 & \multirow{3}{*}{0,052} \\
\hline B & $37(46,3)$ & 36 & $(45,0)$ & 7 & $(8,8)$ & 80 & \\
\hline $\mathrm{C}$ & $4 \quad(80,0)$ & 0 & $(0)$ & 1 & $(20,0)$ & 5 & \\
\hline \multicolumn{8}{|c|}{ Kenar renklenmesi } \\
\hline $\mathbf{A}$ & $21 \quad(35,0)$ & 26 & $(43,3)$ & 13 & $(21,7)$ & 60 & \multirow{3}{*}{0,093} \\
\hline B & $41 \quad(48,2)$ & 35 & $(41,2)$ & 9 & $(10,6)$ & 85 & \\
\hline $\mathrm{C}$ & $4 \quad(80,0)$ & 0 & (0) & 1 & (20) & 5 & \\
\hline \multicolumn{8}{|c|}{ Kenar uyumu } \\
\hline $\mathbf{A}$ & $26(35,6)$ & 33 & $(45,2)$ & 14 & $(19,2)$ & 73 & \multirow{3}{*}{0,309} \\
\hline B & $32(50,8)$ & 24 & $(38,1)$ & 7 & $(11,1)$ & 63 & \\
\hline $\mathrm{C}$ & $8 \quad(57,1)$ & 4 & $(28,6)$ & 2 & $(14,3)$ & 14 & \\
\hline \multicolumn{8}{|c|}{ Sekonder çürük } \\
\hline $\mathbf{A}$ & $48 \quad(40,3)$ & 52 & $(43,7)$ & 19 & $(16,0)$ & 119 & \multirow{3}{*}{0,053} \\
\hline B & $18(60,0)$ & 9 & $(30,0)$ & 3 & $(10,0)$ & 30 & \\
\hline $\mathrm{C}$ & $0 \quad(0)$ & 0 & $(0)$ & 1 & (100) & 1 & \\
\hline \multicolumn{8}{|c|}{ Anatomik form } \\
\hline $\mathbf{A}$ & $23(35,4)$ & 28 & $(43,1)$ & 14 & $(21,5)$ & 65 & \multirow{3}{*}{$\mathbf{0 , 0 3 4}$ * } \\
\hline B & $34(46,6)$ & 32 & $(43,8)$ & 7 & $(9,6)$ & 73 & \\
\hline $\mathrm{C}$ & $9 \quad(75,0)$ & 1 & $(8,3)$ & 2 & $(16,7)$ & 12 & \\
\hline \multicolumn{8}{|c|}{ Postoperatif hassasiyet } \\
\hline $\mathbf{A}$ & $58 \quad(43,3)$ & 57 & $(42,5)$ & 19 & $(14,2)$ & 134 & \multirow{3}{*}{0,136} \\
\hline B & $8 \quad(53,3)$ & 4 & $(26,7)$ & 3 & $(20,0)$ & 15 & \\
\hline $\mathrm{C}$ & $\begin{array}{ll}0 & (0)\end{array}$ & 0 & (0) & 1 & (1) & 1 & \\
\hline \multicolumn{8}{|c|}{ Yüzey pürüzlüllüğï } \\
\hline $\mathbf{A}$ & $14(37,8)$ & 11 & $(29,7)$ & 12 & $(32,4)$ & 37 & \multirow{3}{*}{$0,001 *$} \\
\hline B & $41 \quad(44,1)$ & 46 & $(49,5)$ & 6 & $(6,5)$ & 93 & \\
\hline $\mathrm{C}$ & $11(55,0)$ & 4 & $(20,0)$ & 5 & $(25,0)$ & 20 & \\
\hline
\end{tabular}

$* p<0,05$

Pulpotomi uygulayan hekimin tecrübesi ile restorasyonun retansiyonu arasında istatistiksel açıdan anlamlı bir ilişki tespit edildi $(p=0,012)$. Retansiyon açısından değerlendirildiğinde tamamı düşen iki restorasyonun da uzman hekim grubuna ait olduğu görüldü. Uzmanların yaptığı restorasyonların diş ile olan anatomik uyumunun lisans ve uzmanlık öğrencilerinin yaptıklarına kıyasla istatistiksel olarak anlamlı şekilde fazla olduğu belirlendi $(p=0,034)$. Diğer hekim gruplarına kıyasla uzman hekimlerin yaptığı restorasyonların yüzey pürüzlülük değerlerinin mine dokusununkine anlamlı şekilde daha yakın olduğu tespit edildi $(p=0,001)$. Renk uyumu, kenar renklenmesi, kenar uyumu, sekonder çürük, postoperatif hassasiyet ile hekim tecrübesi arasında anlamlı bir ilişki gözlenmedi $(p>0,05)$. Ağızda bulunan süt dişlerinin ( $n=150$ ) \%15,3'ünde mobilite gözlenirken herhangi birinden kaynaklı abse veya fistül bulgusuna rastlanmadı (Şekil 1). 


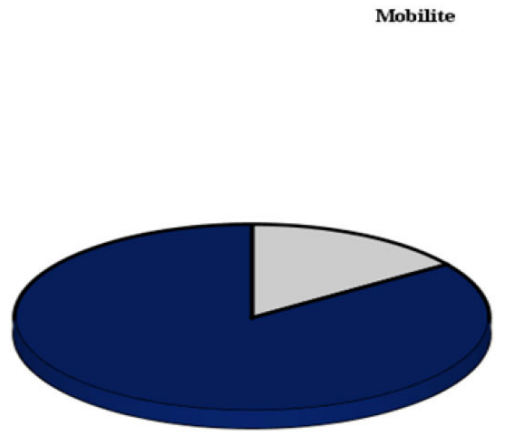

Şekil 1. Pulpotomi tedavisi uygulanan dişlerde mobilite varlığı.

Ağızda yer almayan süt dişlerinin ( $n=120) \% 86,7$ 'sinin fizyolojik olarak düştüğü, \%13,3'ünün ise enfeksiyon nedeniyle kaybedildiği belirlendi (Şekil 2).

Süt dişlerinin kaybedilme sebebi

$\square$ Enfeksiyon

Fizyolojik



Şekil 2. Pulpotomi tedavisi uygulanan süt dişlerinin kaybedilme sebebi. Ağızda bulunmayan süt dişlerinin \%77,5'inin yerine daimi dişlerin sürdüğü görüldü (Şekil 3a.).

Daimi dișin sürmesi Sürmemi

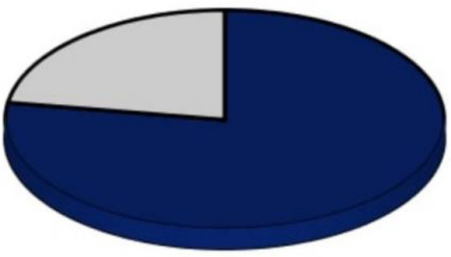

Şekil 3a. Daimi dişlerin sürme durumu.

Süt dişlerinin yerine süren daimi dişlerin \%38,7'sinde rotasyon tespit edilirken \%61,3'ünde herhangi bir anomaliye rastlanmadı (Şekil 3b).

Anomali varhı̆

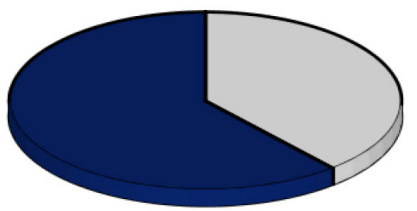

Şekil 3b. Daimi dişte anomali varlığı.
Karşı çenedeki süt dişlerinin \%83,9'unun yerine daimi dişlerin sürdüğü belirlendi (Şekil 4a).

Simetrik daimi dișin sümesi Sürmemis

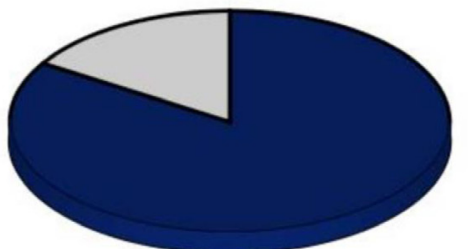

Şekil 4a. Simetrik daimi dişlerin sürme durumu.

Ağıza sürmüş olan simetrik daimi dişlerin \%30,8'inde rotasyon görülürken \%69,2'sinde herhangi bir anomali gözlenmedi (Şekil 4b).

Simetrik daimi diște anomali varlı̆ğ Rotasyon va
Anomali yok

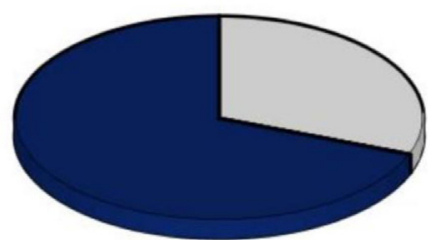

Şekil 4b. Simetrik daimi dişte anomali varlığı.

Pulpotomi uygulanan süt dişlerinin yerine süren daimi dişlerde $(n=28)$ rotasyon varsa süren bütün simetrik daimi dişlerde de rotasyon olduğu görüldü $(p>0,05)$

\section{TARTIŞMA}

Süt dişinin fizyolojik düşme zamanına kadar sağlığını ve bütünlüğünü korumak, yerine gelecek olan daimi diş üzerindeki olası negatif etkilerini engellemek amacıyla gerçekleştirilen pulpotomi uygulamaları, yüksek başarı oranı ile yaygın olarak kullanılan bir tedavi yöntemidir. ${ }^{14,}$ ${ }^{18}$ Süt dişlerinde pulpotomi tedavisi sıkça uygulanmasına rağmen yapılan çalışmaların daha çok pulpotomi materyallerinin karşılaştırılmasına odaklandığı görülmektedir. Pulpotomi sonrası yapılan üst restorasyon ile tedavinin sürekli dişler üzerindeki etkileri ile ilgili literatürde yer alan çalışma sayısı oldukça sınırlıdır. Bu nedenle mevcut çalışmada süt dişlerinde uygulanan pulpotomi tedavileri ve üst restorasyonlarının başarısı ile bu tedavilerin daimi dişlerin gelişim ve sürme sürecine olan etkilerinin değerlendirmesi amaçlandı.

Pulpotomi tedavisi için farklı teknik ve materyaller bulunmaktadır. Süt dişlerindeki pulpotomi tedavisinde hala altın standart olarak kabul edilen formokrezolün insanlarda kullanımı konusunda endişelerin öne çıkmasıyla birlikte alternatif ajanlar geliştirilmiştir. ${ }^{19}$ Kontrollü klinik çalışmalar demir sülfatın formokrezole uygun bir alternatif olduğunu ve klinik başarısının oldukça yüksek olduğunu göster- 
mektedir., ${ }^{5,6}$ Bu çalışmada güçlü bir hemostatik ajan olan demir sülfatın kapaklama ajanı olarak kullanıldığı süt dişi pulpotomi tedavilerinin başarısı değerlendirildi.

Pulpotomi tedavilerindeki başarı oranı bu kavramının kullanım şekline göre değişmektedir. İlgili dişin düşme zamanına kadar ağızda kalması başarı kriteri olarak belirlendiğinde başarı oranı yüksek bulunurken; dişin herhangi bir semptom göstermeden ağızda kalma süresi göz önünde bulundurulduğunda bu oran oldukça düşmektedir. ${ }^{20}$

Pulpotomi tedavilerinde cinsiyet, dişin numarası ve bulunduğu çene gibi faktörlerin tedavi sonuçlarını etkileyebileceği düşünülmektedir. Yapılan çalışmalarda pulpotomi tedavilerinin klinik ve radyografik başarıları üzerinde cinsiyetin etkisi olmadığı gösterilmiştir. ${ }^{20,21}$ Pulpotomi uygulanan dişlerin ağızda bulunma durumu ile cinsiyet arasında anlamlı bir ilişkinin bulunmadığı mevcut çalışmanın sonuçları da bu bulguları desteklemektedir.

Pulpotomi çalışmalarında alt ve üst çene başarı oranları değerlendirildiğinde alt çenede daha fazla başarısızlık gözlenmiştir. Bu durumun üst çenedeki dişlerde radyolojik yansımalar veya alt çenede izolasyon sağlama konusunda yaşanan zorluklardan kaynaklı olabileceği rapor edilmiştir. ${ }^{15,22}$ Pulpotomi uygulanan dişin numarası ve bulunduğu çene ile tedavi başarısı arasında istatistiksel olarak anlamlı bir fark bulunmadığını bildiren çalışmalar da bulunmaktadır. ${ }^{20,22,23}$ Bu çalışmada pulpotomi tedavisi uygulanan üst 1. süt azılarının diğer dişlere kıyasla anlamlı şekilde erken kaybedildiği görüldü. Süt 1. azının mine-dentin kalınlığının süt 2. azıya göre daha az olması ve pulpanın çürükten daha çabuk etkilenmesinin bu durum ile ilişkili olabileceği düşünülmektedir.

Literatürde pulpotomi tedavilerinin başarılarının incelendiği çeşitli çalışmalarda takip süreleri 6 ile 38 ay arasında değişmektedir. ${ }^{20,24}$ Uzun dönem klinik çalışmalar, materyallerin zamana karşı başarılarını daha güvenilir olarak değerlendirme fırsatı vermesine rağmen, bazı durumlarda hasta katılımında azalma nedeniyle bilgi kaybına sebep olarak kesin bir yargıya varılamamasına neden olabilmektedir. ${ }^{25,26}$ Yapılan bir çalışma takip süresi ile pulpotomi tedavilerinin başarısı arasında bir ilişki olmadığını bildirmiştir. ${ }^{21}$ Özer ve ark. ${ }^{27 \prime n ı n ~ b u l g u l a r ı n a ~ b e n z e r ~ s ̧ e k i l d e ~ b u ~}$ çalışmada takip süresi uzadıkça (>24 ay) süt dişlerinde görülen kayıp yüzdelerinin anlamlı derecede arttığı belirlendi.

Süt dişlerine uygulanan pulpotomi tedavilerinin başarısında koronal restorasyonun niteliğinin de önemli bir etken olduğu bilinmektedir.15,28 Pulpotomi tedavisini takiben yapılan üst restorasyon için cam iyonomer, amalgam, kompomer, kompozit veya paslanmaz çelik kuronlar (PÇK) kullanılmaktadır. ${ }^{23,29}$ Amalgamın içeriğindeki civa ve PÇK'ların yüksek maliyeti ile her iki materyalin de estetik olmayan görüntüsü hakkında oluşan ebeveyn kaygıları nedeniyle bu iki materyal çalışmada kullanılmadı. Pulpo- tomi tedavilerinin değerlendirildiği bir çalışmada, PÇK'lar hariç tutulduğunda gözlem süresine bakılmaksızın cam iyonomerin diğer materyallere göre komplikasyon riskini azalttığı kompozitin ise arttırdığı tespit edilmiştir. ${ }^{23}$ Pulpotomi tedavisi uygulanan çekilmiş dişler üzerinde yapılan çalışmalarda, cam iyonomer siman üzerine yerleştirilen PÇK'lara kıyasla rezin içerikli materyallerin marjinal adaptasyonu sağlama konusunda daha iyi olduğu belirlenmiştir. ${ }^{23,30} \mathrm{Bu}$ çalışmada diğer materyallerle karşılaştırıldığında cam iyonomer ile üst restorasyonu yapılan dişlerin ağızda bulunma oranı anlamlı derecede daha düşük bulundu. Diğer materyallere kıyasla cam iyonomerlerin takip süresinin daha fazla olması ve diş dokularına rezin içerikli materyaller kadar güçlü bağlanamaması bu durumu açıklamaktadır.

Bu çalışmada kullanılan restoratif materyaller USPHS kriterlerine göre değerlendirildiğinde; kompozitin yüzey pürüzlülüğünün diğer 2 materyale kıyasla anlamlı şekilde daha fazla olduğu tespit edildi. Ancak farklı restorasyonların özelliklerinin değerlendirildiği başka bir çalışmada yüzey pürüzlülüğü açısından anlamlı bir fark olmadığı bildirilmiştir. ${ }^{31}$ Ayrıca bu çalışmanın marjinal uyum açısından bulgularının Ilie ve ark.'nın yaptığı çalışmaya benzer şekilde olduğu görülmektedir. ${ }^{32}$ Buna göre kompozitlerin marjinal uyumlarının kompomer ve cam iyonomerlere göre daha iyi olduğu belirlendi. Bu farklılığının zaman içinde ağız ortamında cam iyonomer simanın fiziksel özelliklerinde meydana gelen değişimlerden kaynaklandığı düşünülmektedir.

Tedaviyi uygulayan hekimin klinik tecrübesinin endodontik tedavilerin prognozunda etkili olduğunu bildiren çalışmalar bulunmaktadır. ${ }^{33,34}$ Kuo ve ark. ${ }^{20}$ mesleki tecrübeleri farklı diş hekimleri ve stajerlerin pulpotomi tedavilerini değerlendirdikleri çalışmalarında diş hekimlerinin yaptıkları tedavilerin stajyerlerinkine kıyasla anlamlı derecede başarılı olduğunu göstermiştir. Benzer çalışmalarda da endodontik tedavilerdeki düşük başarı oranının stajyer hekimlerin yeterli klinik deneyime sahip olmaması ile ilişkili olabileceği üzerinde durulmuştur. ${ }^{35,36}$ Bu çalışmada lisans öğrencilerinin pulpotomi tedavisi uyguladığı dişlerin ağızda bulunma oranının uzmanlık öğrencilerininkine kıyasla anlamlı düzeyde düşük bulunması literatürdeki çalışmaları desteklemektedir. Ancak uzman diş hekimleri ile diğer hekimler arasında anlamlı bir ilişki bulunmaması uzmanların uyguladığı tedavilerin takip süresinin diğer hekimlerinkinden daha fazla (> 24) olması ile ilişkilendirilebilir.

Hekimin becerisi ya da uygulama sırasında yaptığı hatalar restorasyonların başarısını etkileyen en önemli faktörler arasında yer almaktadır. ${ }^{37}$ Hekim tarafından uygun şekilde yapılan bir restorasyon ile kaybedilen estetik, fonksiyon ve ağız sağlığı tekrar kazanılırken, uygun yapılmayan bir tedavi ciddi sorunlar yaratabilmektedir. Bu çalışmada uzmanların yaptığı restorasyonların diğerlerine kıyasla diş 
ile olan anatomik uyum ve yüzey pürüzlülük değerlerinin mine dokusuna yakınlığının anlamlı derecede daha iyi olduğu görüldü. Bu durum hekimlerin konusunda uzman ve tecrübe sahibi olması ile restorasyon başarısının arttığını göstermektedir. Ancak tamamı düşen iki restorasyonun da uzman hekimler tarafından yapılmasının bu dişlerde restoratif materyal olarak cam iyonomer kullanılması ve takip süresinin 24 aydan fazla olması ile ilişkili olabileceği düşünülmektedir.

Periradiküler dokularda oluşan bir enflamasyonun uzun süre klinik belirti vermeden gelişebileceğini savunan araştırmacılar tedavi sonrası belirli aralıklarla klinik ve radyolojik kontrollerin yapılmasının son derece önemli olduğunu belirtmektedir. ${ }^{38}$ Olczak-Kowalczyk ve ark. ${ }^{23}$ yaptıkları bir çalışmada pulpotomi tedavisinden sonra 31 dişte fistül 1 dişte apse olmak üzere 32 dişte klinik semptom gözlemlemiştir. Bu çalışmada ise pulpotomi uygulanan süt dişlerinin herhangi birinde apse ya da fistül görülmedi. Bu durum çalışmada yer alan hastaların rutin kontrol amaçlı çağrılması ile ilişkili bulunmaktadır. Ayrıca hastaların dişlerinde tedaviden kaynaklı bir enfeksiyon geliştiğinde ilgili dişlerin çekiminin yapılmış olabileceği düşünülmektedir. Süt dişlerine uygulanan pulpal tedaviler gelişen daimi dişleri etkileyebilmektedir. Süt dişi kanal tedavisinin daimi dişler üzerine ve eksfoliasyon zamanına etkisinin incelendiği bir çalışmada, tedavinin daimi dişte mine defekti oluşturabileceği ve tedavi edilen dişlerin kontralateral taraftaki dişlere nazaran daha erken düştüğü saptanmıştır. ${ }^{39}$ Süt azı dişlerinde uygulanan kök kanal tedavisinin daimi dişler üzerindeki uzun dönem etkilerini araştıran Moskovitz ve ark. ${ }^{8}$ bazı daimi dişlerin mine yüzeyinde hipokalsifiye defekt, bazı dişlerde ise rotasyon olduğunu bildirmiştir. Bu çalışmada pulpotomi uygulanan süt dişlerinin yerine süren daimi dişlerde rotasyon tespit edildiğinde simetrik daimi dişlerde de rotasyon olduğu görüldü. Daimi dişlerde rotasyon gelişmesi ile süt dişlerine uygulanan pulpotomi tedavisi arasında anlamlı bir ilişki gözlenmedi.

Hastaların sosyoekonomik durumu, ağız bakım alışkanlıkları, tedavi sırasındaki kooperasyon durumu gibi tedavi başarısını etkileyecek diğer faktörlerin araştıılamaması bu çalışmanın limitasyonları arasında yer almaktadır.

\section{SONUÇ}

Üst restorasyonda kullanılan materyalin koronal örtücülüğü ile tedaviyi uygulan hekimin klinik tecrübe ve becerisi pulpotomi uygulamalarında başarıyı etkileyen önemli faktörlerdendir. Pulpotomi tedavilerinin gelişen daimi diş üzerine etkisini değerlendirmek için uzun dönemli çalışmalara intiyaç duyulmaktadır. Bu çalışmanın kendi koşul ve sınırları içerisinde varılan sonuçların gelecek çalışmalara ışık tutması beklenmektedir.

\section{KAYNAKLAR}

1.Moss SJ. Growing up Cavity Free. A Patient's Guide to Prevention. Quintessence Publishing Co, Inc, Chicago,
1993;32-38.

2.Yıldız E. Süt dişlerinde formokrezol, kalsiyum hidroksit, mineral trioksit agregat (MTA) ve ferrik sülfat amputasyonlarının klinik ve radyografik değerlendirilmesi. Sağlık Bilimleri Enstitüsü, Pedodonti Anabilim Dalı. Doktora Tezi, Konya: Selçuk Üniversitesi, 2009.

3.Carrotte P. Endodontic treatment for children. Br Dent $\mathrm{J}$ 2005; 198: 9-15.

4.Mathewson RJ, Primosch RE. Fundamentals of pediatric dentistry. 3nd ed., Chicago : Quintessence Books; 1995.

5. Huth KC, Hajek-Al-Khatar N, Wolf $\mathrm{P}$, Ilie N, Hickel R et.al. Long-term effectiveness of four pulpotomy techniques: 3-year randomised controlled trial. Clin Oral Investig 2012; 16: 1243-1250.

6.Ibricevic $\mathrm{H}$, Al-Jame Q. Ferric sulfate as pulpotomy agent in primary teeth: twenty month clinical follow-up. J Clin Pediatr Dent 2000; 24: 269-272.

7.Rocha MJdC, Cardoso M. Survival analysis of endodontically treated traumatized primary teeth. Dent Traumatol 2007, 23: 340-347.

8.Moskovitz M, Yahav D, Tickotsky N, Holan G. Long-term follow up of root canal treated primary molars. Int J paediatr dent 2010; 20: 207-213.

9.Bergenholtz G, Hörsted-Bindslev P, Reit C. Textbook of endodontology. 2nd ed., John Wiley \& Sons, 2013.

10.Casas MJ, Layug M, Kenny D, Johnston DH, Judd $P$. Two-year outcomes of primary molar ferric sulfate pulpotomy and root canal therapy. Pediatr Dent 2003; 25: 97102.

11. Ahmed HMA. Pulpectomy procedures in primary molar teeth. European J Gen Dent 2014; 3: 3-10.

12.Moskovitz M, Sammara E, Holan G. JJod. Success rate of root canal treatment in primary molars. J Dent 2005; 33: 41-47.

13.Briso ALF, Rahal V, Mestrener SR, Dezan Junior E. Biological response of pulps submitted to different capping materials. Braz Oral Res 2006; 20: 219-225.

14. American Academy of Pediatric Dentistry. Pulp therapy for primary and immature permanent teeth. The Reference Manual of Pediatric Dentistry. Chicago, Ill.: American Academy of Pediatric Dentistry 2020, 384-392.

15. Holan G, Fuks A, Ketlz N. Success rate of formocresol pulpotomy in primary molars restored with stainless steel crown vs amalgam. Pediatr Dent 2002; 24: 212-216.

16. Alaçam A. Pedodontide endodontik yaklaşımlar. In: Alaçam T, Uzel I, Alaçam A, Aydın M. Endodonti. Ankara, Barış Yayınları. 2000; 693-722.

17.Uzer Çelik E, Yazkan B, Tunaç AT. Posterior direkt restorasyonların klinik performansını etkileyen faktörlerin değerlendirilmesi. EÜ Dişhek Fak Derg 2016; 37: 2: 99-106. 18. Rodd H, Waterhouse P, Fuks A, Fayle S, Moffat M. Pulp therapy for primary molars. Int J Paediatr Dent 2006; 16: 
15-23.

19.Milnes AR. Is formocresol obsolete? A fresh look at the evidence concerning safety issues. Pediatr Dent 2008; 30: 237-246.

20.Kuo H-Y, Lin J-R, Huang W-H, Chiang M-L. Clinical outcomes for primary molars treated by different types of pulpotomy: a retrospective cohort study. J Formos Med Assoc 2018; 117: 24-33.

21.Çelik BN. Süt Dişlerinin Çürüklü Pulpa Perforasyonlarinda MTA Amputasyonunun Başarisinin Değerlendirilmesi. Sağlık Bilimleri Enstitüsü, Pedodonti Anabilim Dalı. Doktora Tezi, Ankara: Ankara Üniversitesi, 2015.

22.Guelmann M, Mcllwain MF, Primosch RE. Radiographic assessment of primary molar pulpotomies restored with resin-based materials. Pediatr Dent 2005; 27: 24-27.

23.Olczak-Kowalczyk D, Samul M, Góra J, Gozdowski D, Turska-Szybka A. Ferric Sulfate and Formocresol pulpotomies in paediatric dental practice. A prospective-retrospective study. Eur J Paediatr Dent 2019; 20: 27-32.

24.MAROTO M, Barberia E, Planells $P$, Godoy FG. Dentin bridge formation after mineral trioxide aggregate (MTA) pulpotomies in primary teeth. Am J Dent 2005; 18: 151154

25.Casas MJ, Kenny DJ, Johnston DH, Judd PL. Longterm outcomes of primary molar ferric sulfate pulpotomy and root canal therapy. Pediatr Dent 2004; 26: 44-48.

26.Peng L, Ye L, Tan H, Zhou X. Evaluation of the formocresol versus mineral trioxide aggregate primary molar pulpotomy: a meta-analysis.Oral Surg Oral Med Oral Pathol Oral Radiol Endod 2006; 102: e40-e44.

27.Özer H. Süt Dişi Pulpa Amputasyonlarinda Uygulanan Farkli Yöntemlerin Klinik Ve Radyolojik Olarak Karşilaştirilmasi. Sağlık Bilimleri Enstitüsü, Pedodonti Anabilim Dalı. Doktora Tezi, Konya: Necmettin Erbakan Üniversitesi, 2017.

28. Kirzioglu Z, Gungor OE, Ciftci ZZ. Evaluation of the restoration success of endodontic therapy of the primary molars. Eur J Dent 2011; 5: 415.

29.Sönmez D, Durutürk L. Ca $(\mathrm{OH}) 2$ pulpotomy in primary teeth. Part I: internal resorption as a complication following pulpotomy. Oral Surg Oral Med Oral Pathol Oral Radiol Endod 2008; 106: e94-e98.

30.Guelmann M, Bookmyer KL, Villalta P, García-Godoy F. Microleakage of restorative techniques for pulpotomized primary molars. J Dent Child 2004; 71: 209-211.

31.Şengül F. Süt Dişi Sinif li Kavitelerinde Farkli Restoratif Materyallerin Başarisinin İn Vivo Ve Sonlu Elemanlar Yöntemi Kullanilarak Değerlendirilmesi. Sağlik Bilimleri Enstitüsü, Doktora Tezi, Pedodonti Anabilim Dali. Erzurum: Atatürk Üniversitesi, 2008.

32.llie N, Hickel R, Valceanu AS, Huth KC. Fracture toughness of dental restorative materials. Clin Oral Invest 2012; 16: $489-498$.
33. Kumar M, Duncan HF. Radiographic evaluation of the technical quality of undergraduate endodontic 'competence' cases in the Dublin Dental University Hospital: an audit. J Ir Dent Assoc 2012; 58: 162-166.

34. Ibrahim AA, Fadlalla NB, Nory NF, Abu-bakr NH. Difficulties in performing root canal treatment among dental students in Sudan. Indian J Dent Res 2012; 3: 196-200.

35. Honey J, Lynch CD, Burke F, Gilmour ASM. Ready for practice? A study of confidence levels of final year dental students at Cardiff University and University College Cork. Eur J Dent Educ 2011; 15: 98-103.

36. Elsayed RO, Abu-bakr NH, Ibrahim YE. Quality of root canal treatment performed by undergraduate dental students at the University of Khartoum, Sudan. Aust Endod $J$ 2011; 37: 56-60.

37. Manhart J, Chen H, Hamm G, Hickel R. Buonocore Memorial Lecture. Review of the clinical survival of direct and indirect restorations in posterior teeth of the permanent dentition. Oper Dent 2004; 29: 481.

38.Toomarian L, Moshref M, Mirkarimi M, Lotfi A, Beheshti M. Radicular cyst associated with a primary first molar: A case report. J Dent (Tahran) 2011; 8: 213.

39.Stallaert KM. A retrospective study of root canal therapy in non-vital primary molars. Faculty of Dentistry, Master Thesis, Department of Pediatric Dentistry. Toronto: Toronto University, 2011. 